\title{
Synthesis and Characterization of Chitosan-Saponin Nanoparticle for Application in Plasmid DNA Delivery
}

\author{
Faruku Bande, ${ }^{1,2}$ Siti Suri Arshad, ${ }^{1}$ Mohd Hair Bejo, ${ }^{1,3}$ \\ Shafiu Abdullahi Kamba, ${ }^{3}$ and Abdul Rahman Omar ${ }^{1,3}$ \\ ${ }^{1}$ Department of Veterinary Pathology and Microbiology, Faculty of Veterinary Medicine, Universiti Putra Malaysia (UPM), \\ 43400 Serdang, Selangor Darul Ehsan, Malaysia \\ ${ }^{2}$ Department of Veterinary Services, Ministry of Animal Health and Fisheries Development, Usman Faruk Secretariat, \\ PMB 2109, Sokoto 840221, Sokoto State, Nigeria \\ ${ }^{3}$ Institute of Bioscience, Universiti Putra Malaysia (UPM), 43400 Serdang, Selangor Darul Ehsan, Malaysia
}

Correspondence should be addressed to Siti Suri Arshad; suri@upm.edu.my

Received 3 April 2015; Revised 25 May 2015; Accepted 28 May 2015

Academic Editor: Subrata Kundu

Copyright (C) 2015 Faruku Bande et al. This is an open access article distributed under the Creative Commons Attribution License, which permits unrestricted use, distribution, and reproduction in any medium, provided the original work is properly cited.

Nonviral delivery system receives attention over the last decade. Chitosan (CS) is a cationic polymer whereas saponin (SP) is classified as glycoside. In this study, a spherically-shaped CS-SP nanoparticle was synthesized and characterized. The ability of the nanoparticle to protect DNA from enzymatic degradation, its thermostability and cytotoxicity were evaluated. The particle size was found below $100 \mathrm{~nm}$ as determined by Zetasizer, transmission electron microscopy (TEM), and field scanning electron microscopy (FSEM) results. The surface charge ranges from $43.7 \mathrm{mV}$ to $38.5 \mathrm{mV}$ before and after encapsulation with DNA plasmid, respectively. In terms of thermostability, Thermal Gravimetric Analysis (TGA) and Differential Scanning Calorimetry (DSC) revealed that CSSP nanoparticle had a melting temperature of $110^{\circ} \mathrm{C}$, with rapid decomposition occurring at $120^{\circ} \mathrm{C}$. Encapsulation of DNA with the synthesized nanoparticle was evidenced by changes in the FTIR spectra including characteristic peaks at 3267.39 and $1635.58 \mathrm{~cm}^{-1}$, wavenumbers. Additional peak was also observed at $1169.7 \mathrm{~cm}^{-1}$ following encapsulation. Electrophoretic mobility showed that CS-SP nanoparticle protected plasmid DNA from enzymatic degradation, while cell viability assays confirmed that the synthesized nanoparticle exhibited low cytotoxicity at different concentrations in avian cells. Taken together these, CS-SP nanoparticle showed potentials for applications as a DNA delivery system.

\section{Introduction}

DNA vaccines are getting considerable attention for use as alternatives in human and veterinary medicines. DNA vaccines are relatively safe and fast to produce and have the ability to stimulate the desired immune responses [1-3]. However, potential limitations, including degradation by endonuclease enzymes in vivo, effect of $\mathrm{pH}$, and low immune response, have hindered their applications in field situation $[1,4,5]$. Thus, there is a growing need to improve their effectiveness in terms of delivery and sustained antigen release [6]. Recent advances in material sciences and nanotechnology allowed significant progress in the use of nonviral vectors for effective gene delivery [7]. Apart from their ability to carry large genes, nonviral vectors are less toxic, making them safe as compared to viral-vector systems [8,9]. Several cationic polymers such as chitosan have been used as biodegradable nanomaterials for gene delivery [7]. Chitosan is a polycationic polysaccharide derived from crustacean as well as insects $[10,11]$. On the other hand, saponin is a naturally occurring glycoside, with the ability to form stable soap-like foams in aqueous solutions. The amphiphilic nature of saponin compounds allows them to carry different antigens or protein for delivery into the cells and also serves as immunomodulators [12]. The aim of this study is to synthesize and characterize a chitosan-saponin (CS-SP) nanoparticle for application in plasmid DNA delivery.

\section{Materials and Methods}

2.1. Synthesis of Chitosan-Saponin Nanoparticles. A $1 \%$ chitosan (75\%-85\% deacetylated) solution (Sigma-Aldrich, 
USA) was prepared by dissolving $0.1 \mathrm{~g}$ of chitosan in $10 \mathrm{~mL}$ distilled water containing $100 \mu \mathrm{L}$ acetic acid (Fisher Scientific, Malaysia). The dissolved mixture was vigorously vortexed for $5 \mathrm{~min}$, sonicated for $30 \mathrm{~min}$, and centrifuged at low speed to remove air bubbles. The $\mathrm{pH}$ of the solution was adjusted to 5.5 by adding $0.1 \mathrm{M}$ sodium hydroxide (Sigma-Aldrich, USA) while continuously stirring as described by Mao et al. [7]. Similarly, about $0.1 \mathrm{~g}$ of saponin (Sigma-Aldrich, USA) was dissolved in $10 \mathrm{~mL}$ of miliQ water (Merk Millipore, Germany) and filtered in $0.22 \mu \mathrm{m}$ filter. To prepare a CS-SP nanoparticle, chitosan $(0.03 \%)$ and saponin $(0.001 \%)$ were mixed and stirred for $5 \mathrm{~min}$ at $500 \mathrm{rpm}$. The $\mathrm{pH}$ of the CS-SP mixture was further adjusted to 5.5 and then filtered through $0.22 \mu \mathrm{m}$ syringe filter (Sartorius, Germany).

\subsection{Preparation of Chitosan-Saponin Encapsulated DNA Plas-} mid. A bivalent IB DNA plasmid designated pBudCR88S1/M41-S1 was encapsulated with a CS-SP nanoparticle to obtain pBudCR88-S1/M41-nanoparticle. Encapsulation was achieved by separate heating of the DNA plasmid as well as CS-SP mixtures at $55^{\circ} \mathrm{C}$ followed by immediate mixing of both plasmid DNA and CS-SP in a single tube and brief vortexing. Final mixture of CS-SP-DNA was obtained at a ratio of $3: 1: 1$ respectively.

\subsection{Characterization of Chitosan-Saponin Nanoparticle}

2.3.1. Transmission Electron Microscopy. The morphology of the synthesized nanoparticle was evaluated by transmission electron microscopy (TEM) using Hitachi H-7100 (Hitachi, Japan). Briefly, a drop of nanoparticle suspension was placed on a parafilm and a carbon coated grid (Agar Scientific, UK) was floated on the nanoparticle drop and kept for $5 \mathrm{~min}$, then, and fixed in $2 \%$ phosphotungstic acid (PTA) (Sigma, USA) for another $5 \mathrm{~min}$. The grid was removed to blot excess liquid and dropped over a Whatman paper (GE Healthcare, UK) in a Petri dish. The grid was further dried in a desiccator and viewed under electron microscope (Hitachi, Japan) [13].

\subsubsection{Field Scanning Electron Microscopy. Field scanning} electron microscopy (FSEM) was used to determine the surface morphology of CS-SP nanoparticle. A drop of CS-SP nanoparticle suspension was placed on a curved aluminum foil and allowed to dry under a beam of light before coating with gold and subsequent viewing under FSEM (JEOL-7600F, USA).

2.3.3. Analysis of Zeta Size and Potentials. The prepared nanoparticle was subjected to zeta size and zeta potential measurements using a dynamic laser light scattering method in a Malvern zeta instrument 3000 (Malvern Instrument, UK) as described previously [7]. Briefly, about $100 \mu \mathrm{L}$ of the sample was resuspended in $900 \mu \mathrm{L}$ miliQ water and added to the cuvette. Measurement was carried out in a temperature of $25^{\circ} \mathrm{C}$ and a scattering angle of $90^{\circ} \mathrm{C}$. Material dispersion and refractive indexes were set at 1.365 and 1.330 (viscosity (CP) 0.8872 ) while dielectric constant was 78.5, respectively [14].
2.3.4. Fourier Transform Infrared Spectroscopy. Fourier transform infrared spectroscopy (FTIR) spectra of the CS-SP encapsulated DNA were evaluated on Nicolet iS 50 FT-IR Spectrometer FTIR-Nexus (Thermo Fisher Scientific Inc., Waltham, MA, USA).

2.3.5. Thermal Gravimetric Analysis. Changes in the thermal properties of nanoparticle were determined using thermogravimetric analyzer, model TGA/SDTA $85^{\mathrm{e}}$ (Mettler Toledo, Switzerland). Briefly, about $200 \mu \mathrm{L}$ of sample was placed in a previously tarred stainless-steel pan and heated from $25^{\circ} \mathrm{C}$ to $250^{\circ} \mathrm{C}$ at the rate of $10^{\circ} \mathrm{C} / \mathrm{min}$ under nitrogen supply of $10 \mathrm{~mL} / \mathrm{min}$.

2.3.6. Differential Scanning Calorimetry. Differential scanning calorimetric analysis was carried out using DSC $823^{\mathrm{e}}$ (Mettler Toledo, Switzerland). About $200 \mu \mathrm{L}$ of the sample was heated from $25^{\circ} \mathrm{C}$ to $300^{\circ} \mathrm{C}$ at the rate of $10^{\circ} \mathrm{C}$ per minute under nitrogen gas carrier supplied at $10 \mathrm{~mL} / \mathrm{min}$.

2.3.7. Protection against Enzymatic Degradation. To determine whether CS-SP nanoparticle is able to protect plasmid DNA against enzymatic degradation, the CS-SP encapsulated DNA plasmids as well as naked DNA plasmids were digested with DNASE1 enzymes at $1 \mathrm{U} / \mu \mathrm{g}$ DNA. The CS-SP encapsulated DNA sample was also treated with chitosanase enzymes to serve as control. For DNASE1 digestion, samples were incubated at $37^{\circ} \mathrm{C}$ for $30 \mathrm{~min}$ following digestion and the reaction was terminated with a stop solution. All mixtures were analyzed for electrophoretic mobility in $0.8 \%$ agarose gel (FirstBase, Selangor, Malaysia) (BioRad, Hercules, CA, USA).

2.3.8. Cytotoxicity by MTT Assay. Cytotoxicity assay was carried out using 3-(4,5-dimethylthiazol-2-yl)-2,5-diphenyl tetrazolium bromide solution (MTT) dye reduction reagent (Sigma-Aldrich, USA) as described previously [15]. A 96well plate was seeded with DF1 cells at $10^{5}$ cells $/ \mathrm{mL}$. The cells were grown in $50 \mu \mathrm{L}$, DMEM media supplemented with $10 \%$ fetal bovine serum. Cells were incubated at $37^{\circ} \mathrm{C}$ for 24 hrs under humidified $5 \% \mathrm{CO}_{2}$. When the cells reached $70-80 \%$ confluence, media were discarded and washed twice with $1 \mathrm{X}$ phosphate buffer saline (PBS) ( $\mathrm{pH} 7.4$ ). The cells were then treated with various concentrations of nanoparticle. Negative control cells were kept untreated; however, Dulbecco's Modified Eagle's Medium (DMEM) was added as mock-treatment. Both treated and control cells were further incubated overnight for $24 \mathrm{hrs}$ under similar condition described in this section. After 24 hours of incubation, cells were washed twice with 1X PBS followed by addition of MTT reagent at a concentration of $0.2-0.5 \mathrm{mg} / \mathrm{mL}$ to each well. Further incubation was carried out for $3 \mathrm{hrs}$ under $5 \% \mathrm{CO}_{2}$ condition. In order to stop the reaction, about $100 \mu \mathrm{L}$ of dimethyl sulfoxide (DMSO) (Sigma-Aldrich) was added to each well for solubilization and the plates were incubated for $30 \mathrm{~min}$ before checking for absorbance at $570 \mathrm{~nm}$ in TECAN sunrise microplate reader (TECAN, Switzerland). Optical densities of treated cells were compared with that of negative control cells and percentage viability was determined 


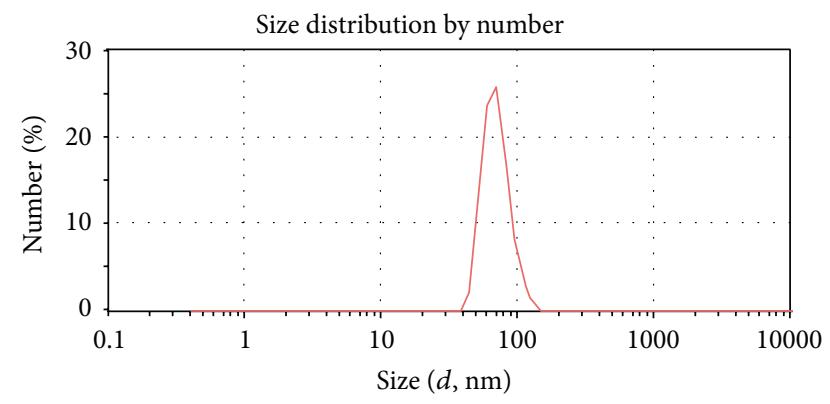

FIGURE 1: Size distribution of CS-SP nanoparticle as revealed by Malvern Zetasizer.

as absorbance of treated/absorbance of control $\times 100$ and expressed in percentage.

\section{Results}

3.1. Synthesis of Chitosan-Saponin Nanoparticles. To obtain a nanoparticle suspension, various approaches such as vortexing, sonication, $\mathrm{pH}$ adjustment, and dilutions were carried out. Optimum size was achieved by premixing for 15-20 sec, followed by sonication for $15 \mathrm{~min}$. The $\mathrm{pH}$ of the mixture was adjusted to 5.5 for maximum chitosan effects. A final mixture of the complexes nanoparticle was achieved by adding $300 \mu \mathrm{g}$ $(0.03 \%)$ chitosan, $100 \mu \mathrm{g}$ saponin, and $100 \mu \mathrm{g}$ plasmid DNA at a ratio of $3: 1: 1$.

3.2. Analysis of Zeta Size. Since particle size is known to affect the interaction and uptake of a nanomaterial at the mucosa level [16], the size distribution of synthesized nanoparticle was evaluated using a Malvern Zetasizer. Mean nanoparticle size for CS-SP was found below $100 \mathrm{~nm}$ with a distribution of $70.67 \mathrm{~nm}$ (Figure 1).

3.3. Analysis of Zeta Potential. Determination of zeta potential was carried out to understand the charges as well as particle stability. Zeta potential for CS-SP nanoparticle was found to be $43.7 \mathrm{mV}$ (Figure 2(a)). However, the particle surface charge decreases to $38.5 \mathrm{mV}$ when negatively charged DNA plasmid was added into the mixture (Figure 2(b)).

3.4. Analysis of Nanoparticle Size by TEM. Results from TEM analysis revealed spherically shaped CS-SP nanoparticle (Figures 3(a) and 3(b)) with sizes ranging from $33.72 \mathrm{~nm}$ to $54 \mathrm{~nm}$ before complexion (a) and up to $79.37 \mathrm{~nm}$ after complexion (b), thus supporting the Zetasizer measurement result. The prepared nanoparticle was relatively homogenous in nature though some particles tend to agglomerate after encapsulation with DNA plasmid (Figures 3(a) and 3(b)).

3.5. Morphological Analysis by SEM. As in TEM, analysis of surface morphology by FSEM revealed that the synthesised CS-SP nanoparticle was spherical in nature. This is similar to that observed under TEM (Figure 4).
3.6. Fourier Transform Infrared Spectroscopy. Fourier transform infrared spectroscopy showed presence of characteristic peaks at $3239.27,1635.31$, and $1279.03 \mathrm{~cm}^{-1}$ chitosan molecule (Figure 5(a)). In the case of saponin, major peaks appeared at 3250.97 and $1635.18 \mathrm{~cm}^{-1}$ (Figure 5(b)). There was a shift in the chitosan peaks after interaction with saponin molecule as evident by characteristic peaks at 3249.09 and $1279.95 \mathrm{~cm}^{-1}$ (Figure 5(c)). On the other hand, following complexion of CS-SP nanoparticle with plasmid DNA, peaks at 3249.04 and $1635.09 \mathrm{~cm}^{-1}$ shifted from lower frequency wavenumbers to a high frequency wavenumbers as 3267.39 and $1635.58 \mathrm{~cm}^{-1}$, respectively. Additional peak was observed at position 1169.7 following encapsulation with DNA plasmid (Figure 5(d)).

3.7. Thermal Gravimetric Analysis. Chitosan-nanosaponin recorded a sharp degradation at a temperature of about $110^{\circ} \mathrm{C}$, thus indicating its melting temperature. There was an observable weight loss occurring from a temperature of $135^{\circ} \mathrm{C}$ to $280^{\circ} \mathrm{C}$ leaving only about $2.3 \%$ remnant of the total product (Figures 6(a) and 6(b)).

3.8. Differential Scanning Calorimetry. The glass transition temperature of the CS-SP nanoparticle was found to be $55.78^{\circ} \mathrm{C}$ and its stability reached $120^{\circ} \mathrm{C}$, thus suggesting the optimum thermal stability of the product as shown in its endothermic peak (Figure 6(b)).

3.9. Protection against Enzymatic Degradation. The protective efficacy of CS-SP against enzymatic degradation was evaluated following treatment of encapsulated DNA plasmids with DNASE1 enzyme. The result indicates complete protection of the CS-SP encapsulated DNA as evident by the absence of DNA mobility in lanes 3 and 5, respectively. In contrast, DNA mobility was evident in CS-SP encapsulated DNA treated with chitosanase enzymes which removes chitosan (lane 6). Naked DNA group treated with DNASE1 did not show evidence of DNA band since the enzymes already degraded the unprotected DNA plasmid (Figure 7).

3.10. Cytotoxicity Assay. Percentage cell viability was used to determine the toxicity of CS, SP and CS-SP nanoparticle in chicken secondary fibroblast cells (DF1). Various concentrations ranging from $2500 \mathrm{mg} / \mathrm{mL}$ to $0.008 \mathrm{mg} / \mathrm{mL}$ were used. Chitosan was shown to be less toxic having cell viability of more than $50 \%$ even at $500 \mathrm{mg} / \mathrm{mL}$ concentration. On the other hand saponin was only nontoxic at $4 \mathrm{mg} / \mathrm{mL}$ concentration. Combination of chitosan and saponin in the nanoparticle led to a drastic reduction in the toxicity of saponin; thus, treatment with chitosan-nanosaponin resulted in more than $50 \%$ cell viability even at a concentration of $100 \mathrm{mg} / \mathrm{mL}$ (Figure 8).

\section{Discussion}

There is a growing interest in the use of nonviral vector as alternatives in gene delivery [17]. In this study, a CS-SP nanoparticle was synthesized and characterized for possible use in plasmid DNA vaccine delivery. Preparation of the 


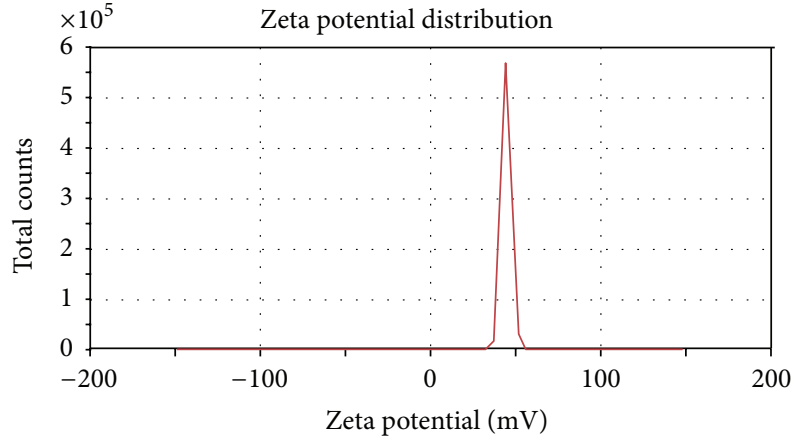

(a)

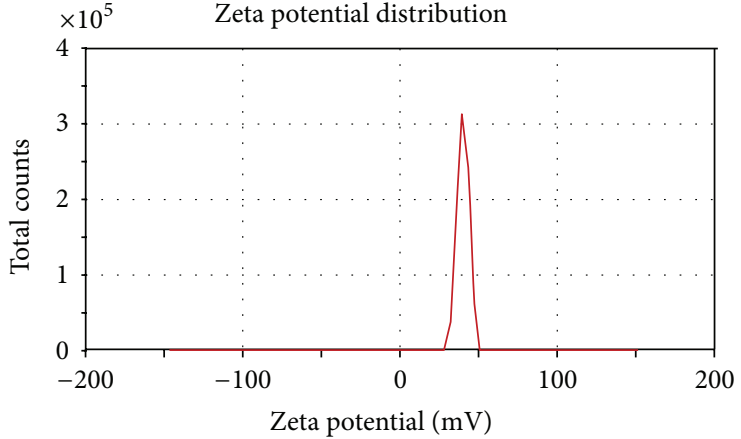

(b)

FIGURE 2: (a) Surface charges of chitosan-saponin nanoparticle before complexion with DNA. (b) Surface charges of CS-SP nanoparticle as determined by zeta potentials.
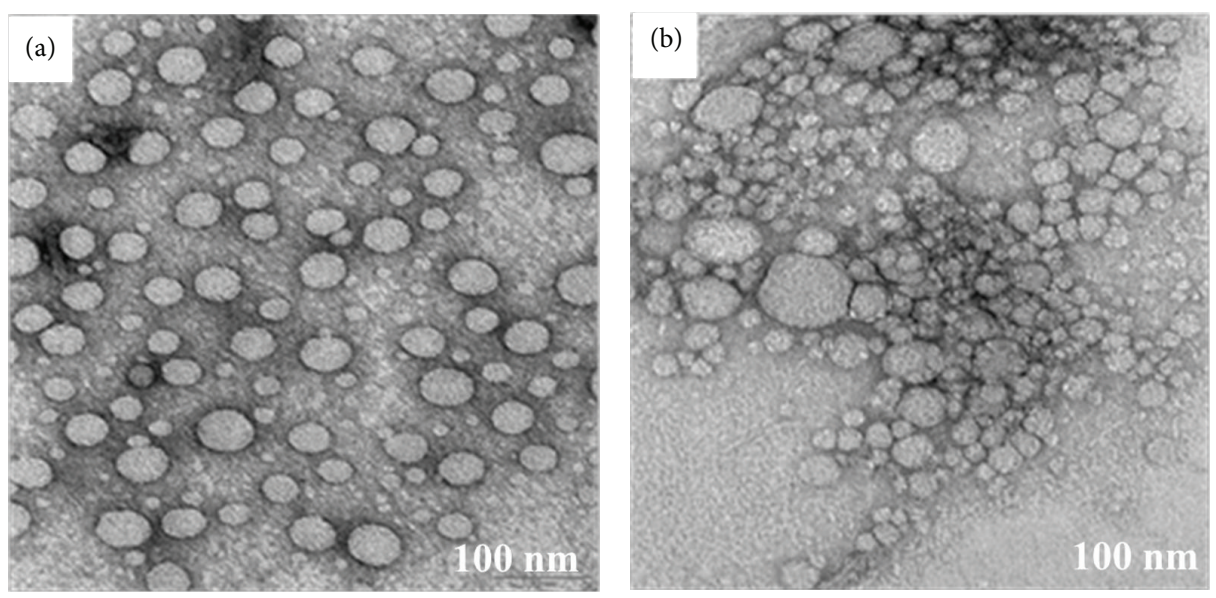

FIGURE 3: Transmission electron microscopy (TEM) showing a spherically shaped CS-SP nanoparticle before (a) and after (b) encapsulation with DNA plasmid. Bar $=100 \mathrm{~nm}$.

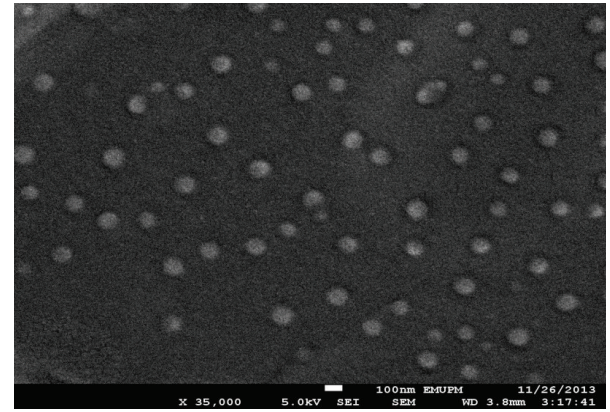

FIGURE 4: Surface morphology of CS-SP nanoparticle as revealed by field scanning electron microscopy (FSEM). Bar $=100 \mathrm{~nm}$.

nanomaterial was achieved through adjustment of parameters such as $\mathrm{pH}$ as reported in previous studies [7, 15]. Apart from the ability of the chitosan to deliver vaccine antigen, the incorporated saponin has the advantage of acting as adjuvant or an immunomodulatory molecule to enhance immune response. This property was reported in saponin or ISCOM-based antigens [18-20]. Thus incorporation of saponin in this study might boost immune response in an in vivo system.

The synthesized nanoparticle was found within the nano range as evident by the zeta sizer result result and corroborated by TEM and SEM analyses. Interestingly, the size and particle morphology observed in this study are consistent with previous reports [15]. However, some studies reported large sizes of particle ranging from 170 to $580 \mathrm{~nm}$. This variation could be as a result of the preparation methods, $\mathrm{pH}$, and nature of starting materials used to synthesize the particle $[21,22]$. Studies have also shown than a smaller particle of less than $10 \mu \mathrm{m}$ is usually phagocytized by antigen presenting cells such as macrophages and dendritic cells, thus favoring the presentation of vaccine antigen [23].

The overall surface charges for CS-SP nanoparticle remained high, despite addition of a negatively charged DNA containing phosphate group. The strong positive charges are likely associated with chitosan, which is known to possess high positive charges at a $\mathrm{pH}$ of about 5-6 due to of protonation of amino group $\mathrm{NH}_{3}{ }^{+}$in the presence of acetic acid medium. Other studies reported strong positive surface 


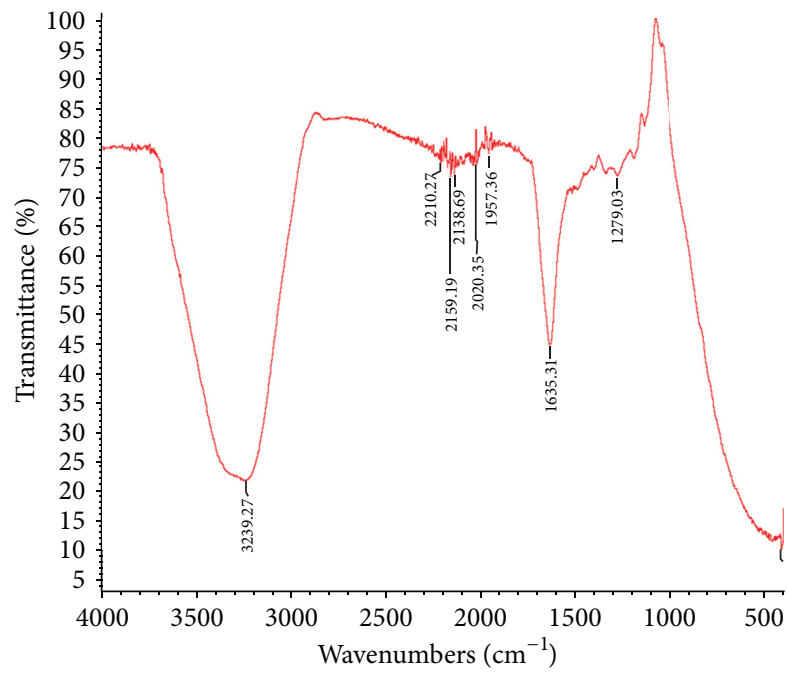

(a)

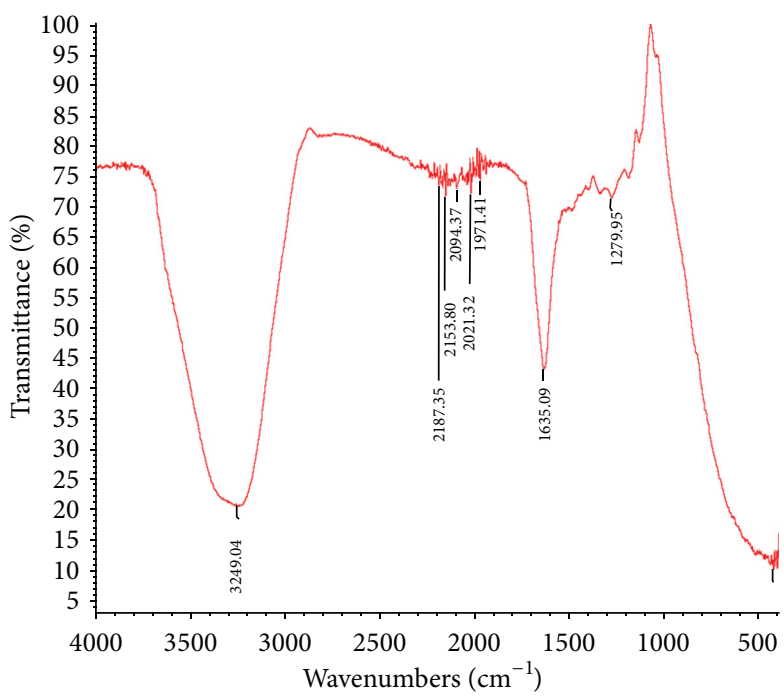

(c)

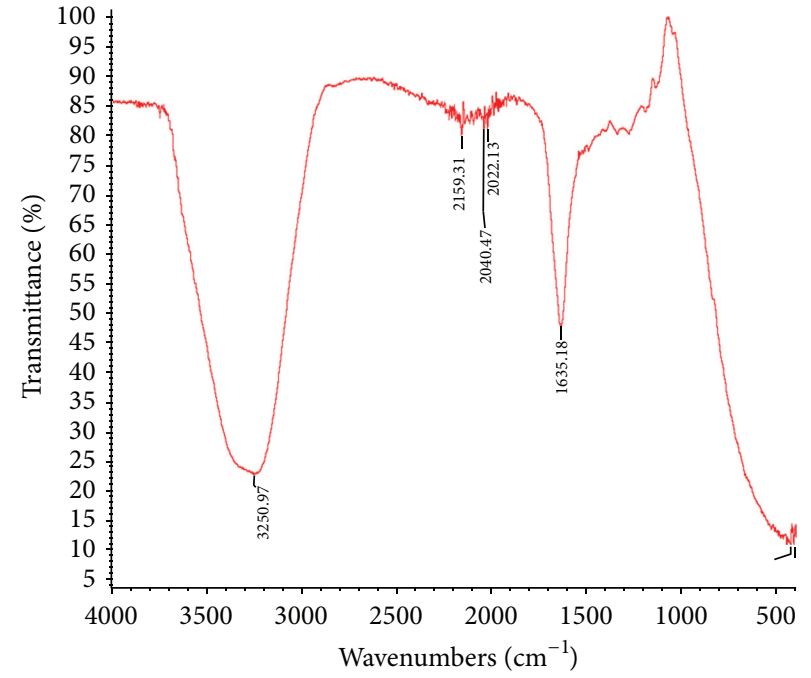

(b)

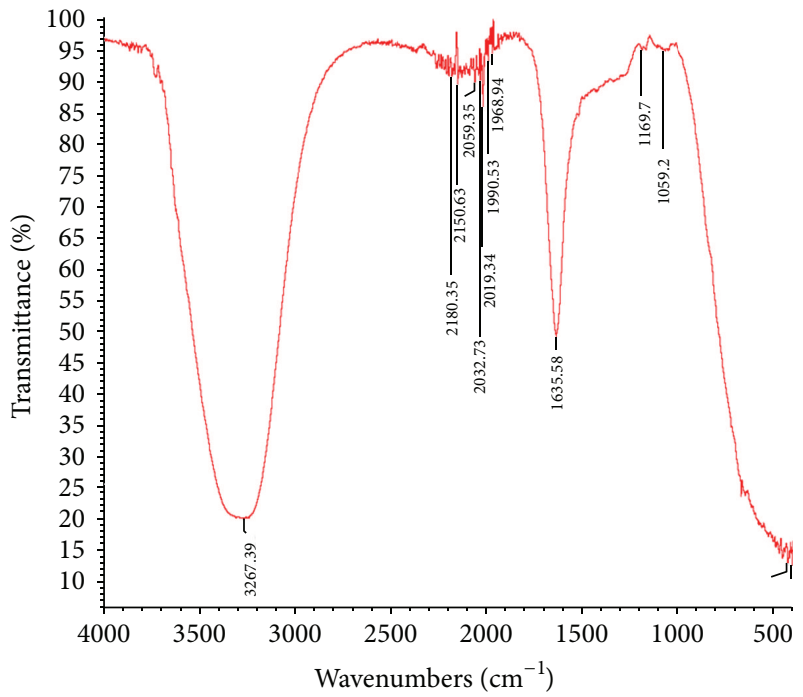

(d)

FIGURE 5: Fourier transform infrared spectra of chitosan (a), saponin (b), chitosan-saponin nanoparticle (c), and chitosan-saponin-DNA complexion (d).

charges in chitosan as well [24]. Adjustment of $\mathrm{pH}$ was similarly reported to affect the charges since $\mathrm{NaOH}$ may form the source of a hydroxyl group which may interact with protons $(\mathrm{H}+)$ of the amine group in chitosan, thus rendering it deprotonated [25].

Changes in the FTIR peaks observed at 3239.27, 1635.31, and $1279.03 \mathrm{~cm}^{-1}$ positions in the chitosan compound are likely associated with primary amine (-NH2), amide $(-\mathrm{CONH} 2)$, and aromatic amine $(\mathrm{C}-\mathrm{N})$, respectively, present in chitosan. Similar result has been observed in other studies $[15,22]$. On the other hand, major peaks occurring at 3250.97 and $1635.18 \mathrm{~cm}^{-1}$ in saponin compound might indicate a broad and strong stretching vibration resulting from hydrogen bonding $(\mathrm{O}-\mathrm{H})$ as well as a medium stretching due to secondary carbon $(\mathrm{C}=\mathrm{C})$ bonding, respectively $[15]$.
Interaction of chitosan with saponin might have caused some peaks located at 3239.27 and $1279.03 \mathrm{~cm}^{-1}$ to shift from lower frequency wavenumbers to high frequency wavenumbers as indicated in 3249.09 and $1279.95 \mathrm{~cm}^{-1}$, respectively. Similarly, peak at $1635.31 \mathrm{~cm}^{-1}$ was observed to shift from high to a lower frequency wavenumber as $1635.09 \mathrm{~cm}^{-1}$ in CS-SP nanoparticle. This may suggest hydrogen but not ionic interaction between the two compounds [15].

Increase in frequency of CS-SP peaks at 3267.39 and $1635.58 \mathrm{~cm}^{-1}$ in addition to the absence of signature peak at $1279.95 \mathrm{~cm}$ as well as appearance of new peak at position $1169.7 \mathrm{~cm}^{-1}$ also indicates interaction between CS-SP nanoparticle and the DNA compound. Evidently, the later peak indicates a stretching vibration probably due to phosphate group $(\mathrm{P}=\mathrm{O})$ and ester bonding in the DNA molecules. 


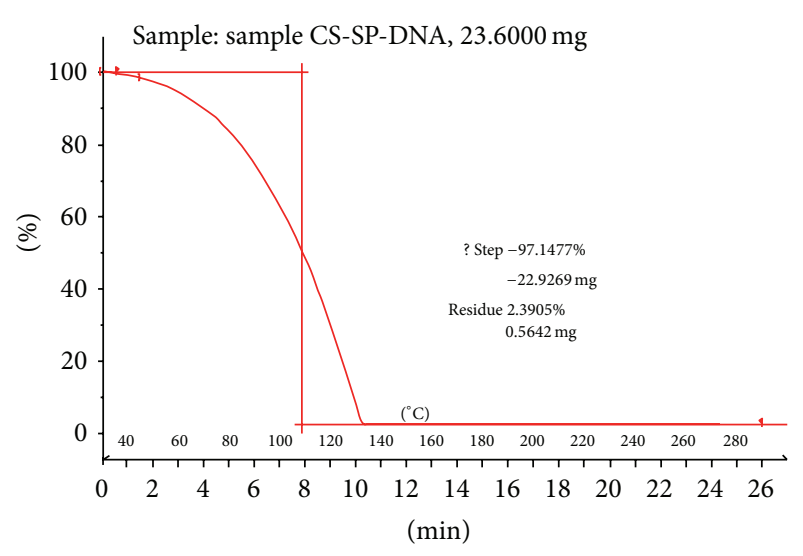

(a)

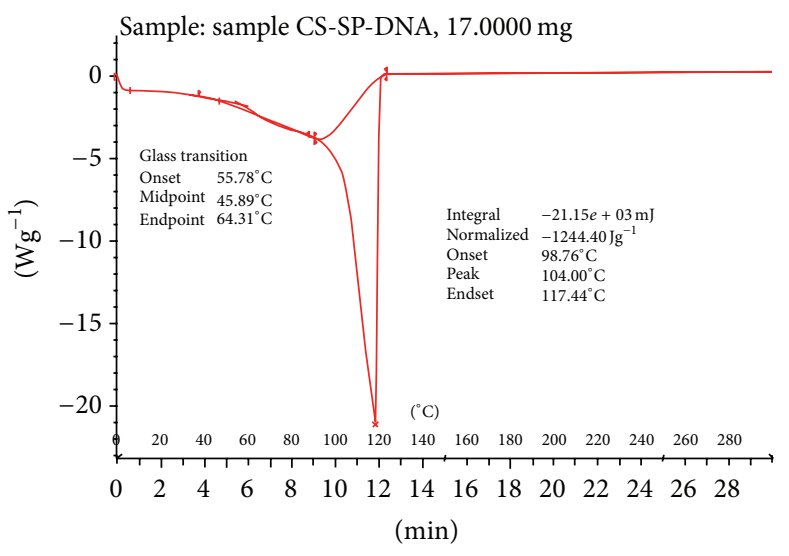

(b)

FIgURE 6: (a) Thermogravimetric analysis, curve showing melting temperature and \% residue left following heating of chitosan-saponin nanoparticle. (b) Thermal stability of chitosan-saponin nanoparticle as revealed by differential scanning calorimetry.

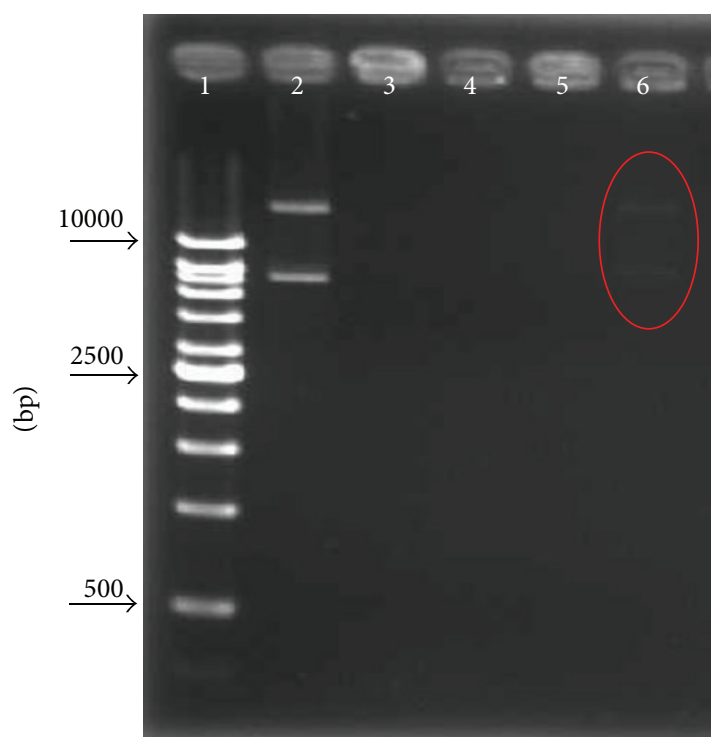

FIGURE 7: Protective capacity of CS-SP nanoparticle against enzymatic degradation of DNA plasmid. Lane 1: $1 \mathrm{~kb}$ ladder (Viventis, Malaysia); lane 2: naked untreated DNA; lane 3: CS-SP-DNA without enzymatic treatment; lane 4: naked DNA treated with DNASE1; lane 5: CS-DNA-SP treated with DNASE1; lane 6: CS-SP-DNA treated with chitosanase which removes the chitosan protection and exposes the DNA plasmid.

This may result from competitive displacement following encapsulation of the DNA [26].

In the thermal study, both TGA and DSC analyses confirmed that CS-SP DNA nanoparticle is thermostable, thus suggesting its potential application in plasmid vaccines used in a field situation. However, other studies have reported a much highly stable compound able to resist a temperature of $500^{\circ} \mathrm{C}[15]$. The variation could be associated with disparity in water content between the two mixtures. It is expected that rapid weight loss may occur as a result of dehydration of the anhydrous glycosidic ring [27]. In addition, the use

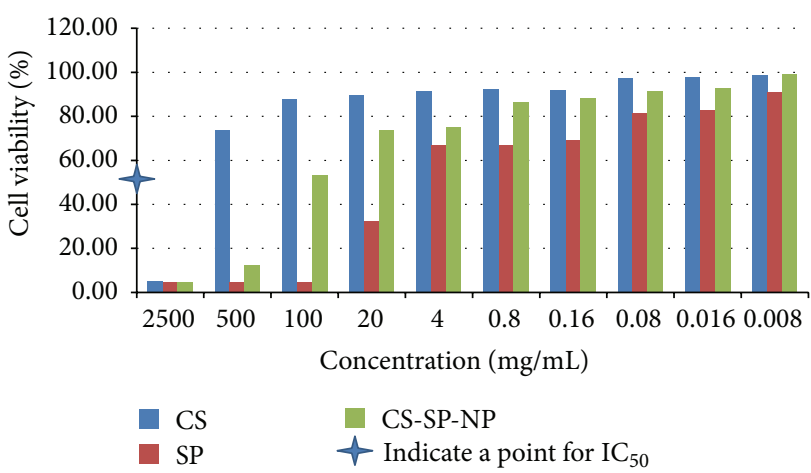

FIGURE 8: Determination of cell viability by MTT assay following treatment of DF1 cells with different concentrations of CS, SP, and CS-SP-DNA nanoparticle.

of tripolyphosphate (TPP) in Rejinold et al. [15] might have caused modification in the crystalline nature of both chitosan and saponin, thus making the two molecules more stable on heating. Other studies have also reported a good stability in either chitosan alone, as CS-SP, or in combination with other compounds $[15,21,26]$.

Enzymatic degradation has been the major concern in plasmid DNA delivery [28]. In this study, encapsulation of plasmid DNA with CS-SP nanoparticle was shown to protect DNA from enzymatic degradation. This is thought to be majorly associated with a highly positive charged chitosan, surrounding both saponin and DNA molecules. In contrast, naked unprotected plasmid was shown to be degraded following enzymatic digestion. These findings agree with other reports demonstrating the ability of chitosan derived nanoparticle to protect DNA from DNASE1 enzyme in vitro $[21,29,30]$.

In terms of toxicity, both CS and CS-SP nanoparticles were shown to be nontoxic at relatively high concentrations; in contrast, saponin was found to be toxic at a relatively high concentration. Several studies have reported the nontoxic 
nature of chitosan in various cells, though most studies used a non-avian cell model $[7,21]$. On the other hand, saponin alone or in combination with other molecules was reported to exhibit selective cytotoxicity in cancer cells and nontoxic at low concentration in normal cos-7, vero, L929, and NIH-3T3 cells $[12,15]$. This suggests its addition as immunomodulator in a delivery system [22].

\section{Conclusion}

In this study, a CS-SP nanoparticle was synthesized and characterized. Based on the size, morphology, thermostability, protection against DNASE1 digestion, and cytotoxicity assays, it could be concluded that CS-SP nanoparticle has potentials for biological application as DNA delivery system.

\section{Conflict of Interests}

The authors of this study report no conflict of interests in the work.

\section{Acknowledgments}

This study was funded by Ministry of Science, Technology and Innovations (MOSTI) Project no. 02-01-04-SF1070. The authors would like to acknowledge technical assistance from MI SAEED.

\section{References}

[1] L. Haygreen, F. Davison, and P. Kaiser, "DNA vaccines for poultry: the jump from theory to practice," Expert Review of Vaccines, vol. 4, no. 1, pp. 51-62, 2005.

[2] B. Ferraro, M. P. Morrow, N. A. Hutnick, T. H. Shin, C. E. Lucke, and D. B. Weiner, "Clinical applications of DNA vaccines: current progress," Clinical Infectious Diseases, vol. 53, no. 3, pp. 296-302, 2011.

[3] M. A. Liu, "DNA vaccines: an historical perspective and view to the future," Immunological Reviews, vol. 239, no. 1, pp. 62-84, 2011.

[4] M. E. Barry, D. Pinto-González, F. M. Orson, G. J. McKenzie, G. R. Petry, and M. A. Barry, "Role of endogenous endonucleases and tissue site in transfection and CpG-mediated immune activation after naked DNA injection," Human Gene Therapy, vol. 10, no. 15, pp. 2461-2480, 1999.

[5] D. P.-G. Howell, R. J. Krieser, A. Eastman, and M. A. Barry, "Deoxyribonuclease II is a lysosomal barrier to transfection," Molecular Therapy, vol. 8, no. 6, pp. 957-963, 2003.

[6] J. J. Donnelly, B. Wahren, and M. A. Liu, "DNA vaccines: progress and challenges," The Journal of Immunology, vol. 175, no. 2, pp. 633-639, 2005.

[7] H.-Q. Mao, K. Roy, V. L. Troung-Le et al., "Chitosan-DNA nanoparticles as gene carriers: synthesis, characterization and transfection efficiency," Journal of Controlled Release, vol. 70, no. 3, pp. 399-421, 2001.

[8] W. Wang, W. Li, N. Ma, and G. Steinhoff, "Non-viral gene delivery methods," Current Pharmaceutical Biotechnology, vol. 14, no. 1, pp. 46-60, 2013.

[9] A. R. Gascón, A. del Pozo-Rodríguez, and M. Á. Solinís, "Nonviral delivery systems in gene therapy," in Gene Therapy - Tools and Potential Applications, chapter 1, InTech, Rijeka, Croatia, 2013.

[10] K. Kurita, "Chitin and chitosan: functional biopolymers from marine crustaceans," Marine Biotechnology, vol. 8, no. 3, pp. 203-226, 2006.

[11] F. A. A. Sagheer, M. A. Al-Sughayer, S. Muslim, and M. Z. Elsabee, "Extraction and characterization of chitin and chitosan from marine sources in Arabian Gulf," Carbohydrate Polymers, vol. 77, no. 2, pp. 410-419, 2009.

[12] O. Kenji, H. Matsuda, T. Murakami, S. Katayama, T. Ohgitani, and M. Yoshikawa, "Adjuvant and haemolytic activities of 47 saponins derived from medicinal and food plants," Biological Chemistry, vol. 381, no. 1, pp. 67-74, 2000.

[13] L. Quaroni and G. Chumanov, "Preparation of polymer-coated functionalized silver nanoparticles," Journal of the American Chemical Society, vol. 121, no. 45, pp. 10642-10643, 1999.

[14] İ. Özcan, E. Azizoğlu, T. Şenyiğit, M. Özyazıcı, and Ö. Özer, "Enhanced dermal delivery of diflucortolone valerate using lecithin/chitosan nanoparticles: in-vitro and in-vivo evaluations," International Journal of Nanomedicine, vol. 8, pp. 461475, 2013.

[15] N. S. Rejinold, M. Muthunarayanan, K. Muthuchelian, K. P. Chennazhi, S. V. Nair, and R. Jayakumar, "Saponin-loaded chitosan nanoparticles and their cytotoxicity to cancer cell lines in vitro," Carbohydrate Polymers, vol. 84, no. 1, pp. 407-416, 2011.

[16] Q. Gan and T. Wang, "Chitosan nanoparticle as protein delivery carrier-systematic examination of fabrication conditions for efficient loading and release," Colloids and Surfaces B: Biointerfaces, vol. 59, no. 1, pp. 24-34, 2007.

[17] S. Mansouri, P. Lavigne, K. Corsi, M. Benderdour, E. Beaumont, and J. C. Fernandes, "Chitosan-DNA nanoparticles as non-viral vectors in gene therapy: strategies to improve transfection efficacy," European Journal of Pharmaceutics and Biopharmaceutics, vol. 57, no. 1, pp. 1-8, 2004.

[18] J. A. Mumford, D. Jessett, U. Dunleavy et al., "Antigenicity and immunogenicity of experimental equine influenza ISCOM vaccines," Vaccine, vol. 12, no. 9, pp. 857-863, 1994.

[19] B. Rönnberg, M. Fekadu, and B. Morein, "Adjuvant activity of non-toxic Quillaja saponaria Molina components for use in ISCOM matrix," Vaccine, vol. 13, no. 14, pp. 1375-1382, 1995.

[20] N. S. Wilson, B. Yang, A. B. Morelli et al., "ISCOMATRIX vaccines mediate CD8 T-cell cross-priming by a MyD88dependent signaling pathway," Immunology and Cell Biology, vol. 90, no. 5, pp. 540-552, 2012.

[21] C. D. Cambridge, S. R. Singh, A. B. Waffo, S. J. Fairley, and V. A. Dennis, "Formulation, characterization, and expression of a recombinant MOMP Chlamydia trachomatis DNA vaccine encapsulated in chitosan nanoparticles," International Journal of Nanomedicine, vol. 8, pp. 1759-1771, 2013.

[22] S. Dehghan, M. T. Kheiri, M. Tabatabaiean, S. Darzi, and M. Tafaghodi, "Dry-powder form of chitosan nanospheres containing influenza virus and adjuvants for nasal immunization," Archives of Pharmacal Research, vol. 36, no. 8, pp. 981-992, 2013.

[23] Y. Waeckerle-Men, E. U.-V. Allmen, B. Gander et al., "Encapsulation of proteins and peptides into biodegradable poly(D,Llactide-co-glycolide) microspheres prolongs and enhances antigen presentation by human dendritic cells," Vaccine, vol. 24, no. 11, pp. 1847-1857, 2006.

[24] N. Saïed and M. Aider, "Zeta potential and turbidimetry analyzes for the evaluation of chitosan/phytic acid complex formation," Journal of Food Research, vol. 3, no. 2, p. 71, 2014. 
[25] U. Konietzny and R. Greiner, "Phytic acid: properties and determination," in Encyclopedia of Food Sciences and Nutrition, pp. 4546-4555, Academic Press, 2nd edition, 2003.

[26] W. Liu, S. Sun, Z. Cao et al., "An investigation on the physicochemical properties of chitosan/DNA polyelectrolyte complexes," Biomaterials, vol. 26, no. 15, pp. 2705-2711, 2005.

[27] R. D. Bhumkar and V. B. Pokharkar, "Studies on effect of $\mathrm{pH}$ on cross-linking of Chitosan with sodium tripolyphosphate: a technical note," AAPS PharmSciTech, vol. 7, no. 2, pp. E138E143, 2006.

[28] M. Köping-Höggård, I. Tubulekas, H. Guan et al., "Chitosan as a nonviral gene delivery system. Structure-property relationships and characteristics compared with polyethylenimine in vitro and after lung administration in vivo," Gene Therapy, vol. 8, no. 14, pp. 1108-1121, 2001.

[29] Z. Liu, D. Lv, S. Liu et al., "Alginic acid-coated chitosan nanoparticles loaded with legumain DNA vaccine: effect against breast cancer in mice," PLOS ONE, vol. 8, no. 4, Article ID e60190, 2013.

[30] J. Chen, B. Tian, X. Yin et al., "Preparation, characterization and transfection efficiency of cationic PEGylated PLA nanoparticles as gene delivery systems," Journal of Biotechnology, vol. 130, no. 2, pp. 107-113, 2007. 

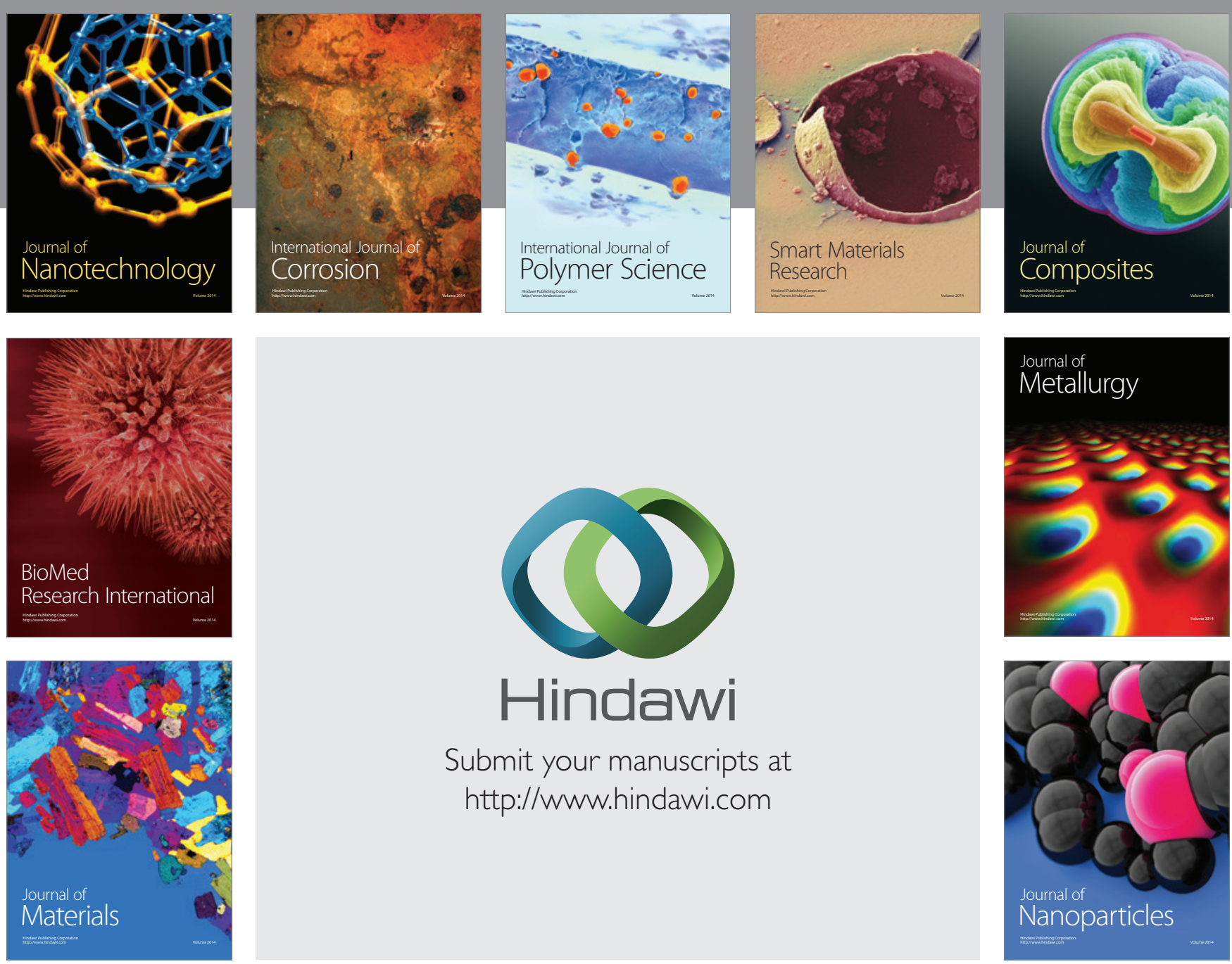

Submit your manuscripts at http://www.hindawi.com
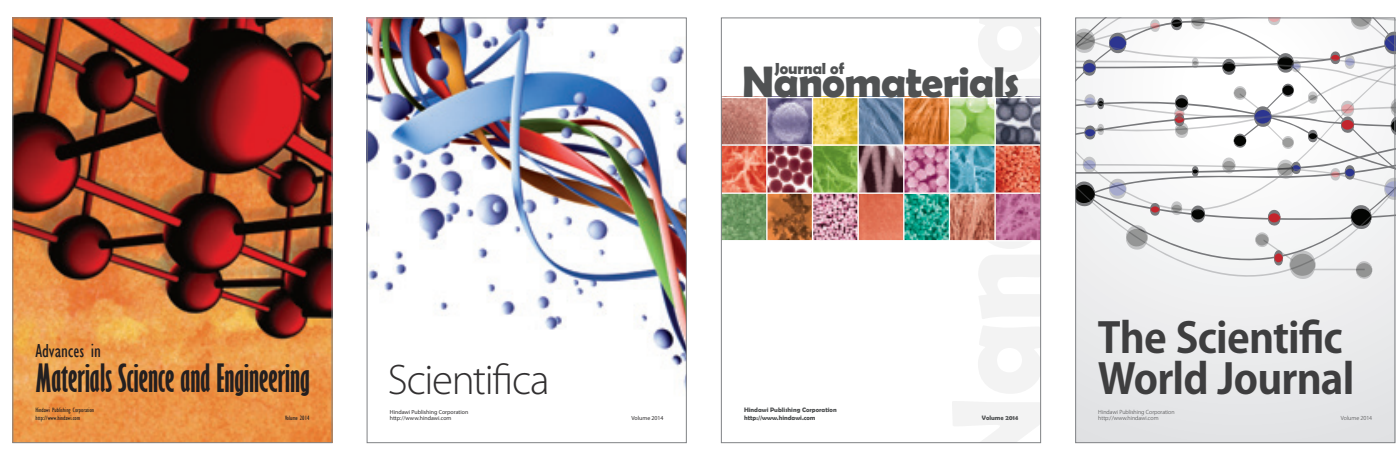

\section{The Scientific World Journal}
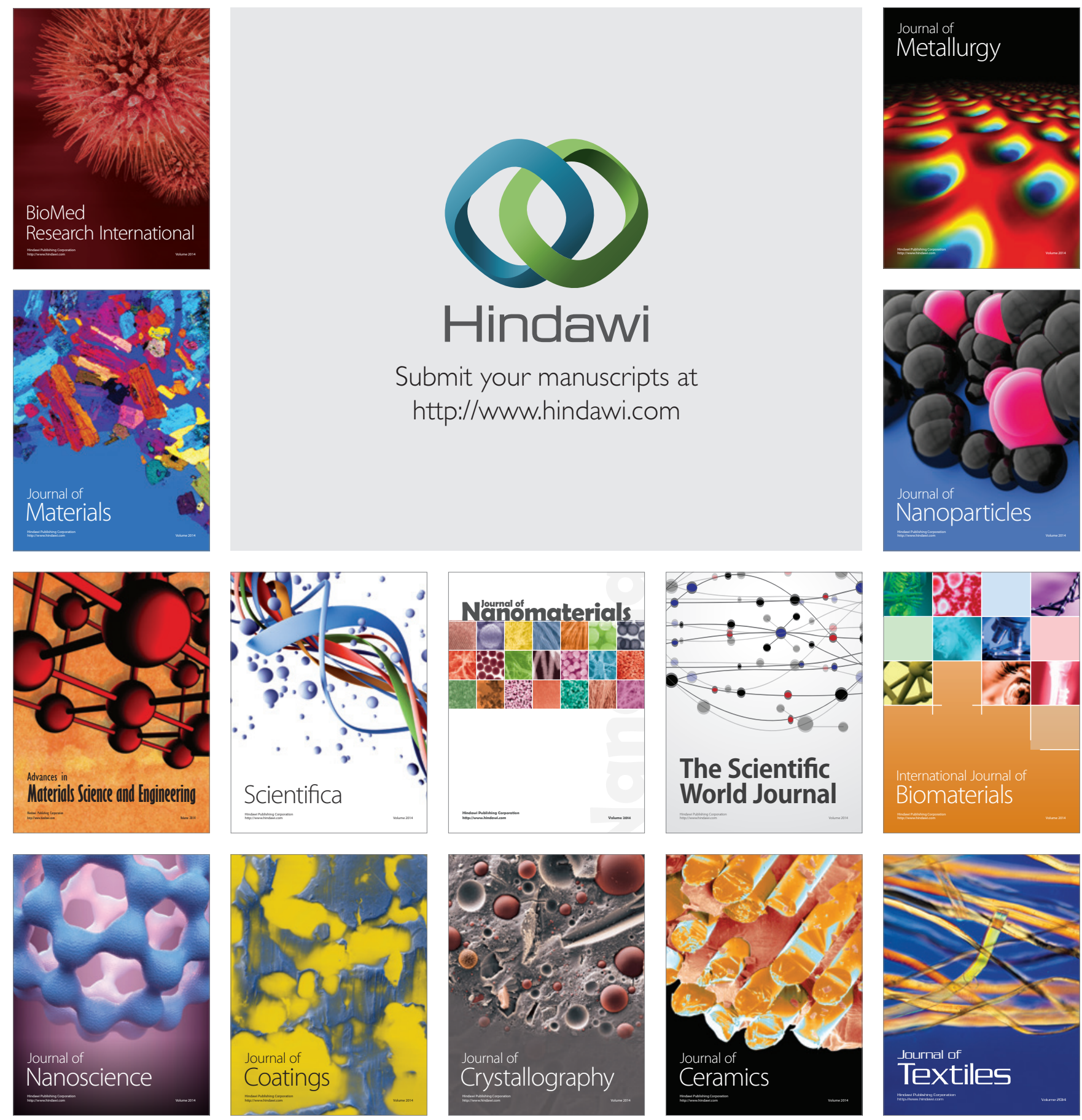